\title{
Influenza Transmission Dynamics in Urban Households, Managua, Nicaragua, 2012-2014
}

\author{
Aubree Gordon, Tim K. Tsang, Benjamin J. Cowling, Guillermina Kuan, Sergio Ojeda, \\ Nery Sanchez, Lionel Gresh, Roger Lopez, Angel Balmaseda, Eva Harris
}

\begin{abstract}
$\underset{\text { MDUCATION }}{\text { Medscape ACTIVITY }}$

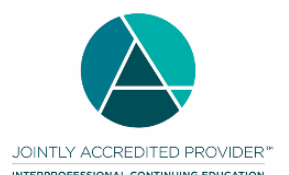

JOINTLY ACCREDITED PROVIDER

In support of improving patient care, this activity has been planned and implemented by Medscape, LLC and Emerging Infectious Diseases. Medscape, LLC is jointly accredited by the Accreditation Council for Continuing Medical Education (ACCME), the Accreditation Council for Pharmacy Education (ACPE), and the American Nurses Credentialing Center (ANCC), to provide continuing education for the healthcare team.

Medscape, LLC designates this Journal-based CME activity for a maximum of 1.00 AMA PRA Category 1 Credit(s) ${ }^{\mathrm{TM}}$. Physicians should claim only the credit commensurate with the extent of their participation in the activity.

All other clinicians completing this activity will be issued a certificate of participation. To participate in this journal CME activity: (1) review the learning objectives and author disclosures; (2) study the education content; (3) take the post-test with a $75 \%$ minimum passing score and complete the evaluation at http://www.medscape.org/journal/eid; and (4) view/print certificate. For CME questions, see page 1972.
\end{abstract}

\section{Release date: September 13, 2018; Expiration date: September 13, 2019}

\section{Learning Objectives}

Upon completion of this activity, participants will be able to:

- Describe overall risk for influenza infection in household contacts, mean serial interval for withinhousehold transmission, and transmissibility of different strains in low-income urban households in Managua, Nicaragua, according to a case-ascertained study

- Explain risk factors for transmission of influenza virus within low-income urban households in Managua, Nicaragua, according to a case-ascertained study

- Determine clinical implications of findings regarding the transmission of influenza virus in lowincome urban households in Managua, Nicaragua, according to a case-ascertained study

\section{CME Editor}

Kristina B. Clark, PhD, Copyeditor, Emerging Infectious Diseases. Disclosure: Kristina B. Clark, PhD, has disclosed no relevant financial relationships.

\section{CME Author}

Laurie Barclay, MD, freelance writer and reviewer, Medscape, LLC. Disclosure: Laurie Barclay, MD, has disclosed the following relevant financial relationships: owns stock, stock options, or bonds from Pfizer.

\section{Authors}

Disclosures: Aubree Gordon, PhD, MPH; Tim K. Tsang, PhD; Guillermina Kuan, MS; Sergio Ojeda, MD; Nery Sanchez, MD; Lionel Gresh, PhD; Roger Lopez, MPH; Angel Balmaseda, MD; and Eva Harris, PhD, have disclosed no relevant financial relationships. Benjamin J. Cowling, PhD, has disclosed the following relevant financial relationships: received grants for clinical research from Sanofi Pasteur.

Author affiliations: University of Michigan, Ann Arbor, Michigan, USA (A. Gordon); The University of Hong Kong, Hong Kong, China (T.K. Tsang, B.J. Cowling); Ministry of Health, Managua, Nicaragua (G. Kuan, R. Lopez, A. Balmaseda); Sustainable Sciences Institute, Managua (S. Ojeda, N. Sanchez, L. Gresh); University of California, Berkeley, California, USA (E. Harris)

DOI: https://doi.org/10.3201/eid2410.161258
During August 2012-November 2014, we conducted a case ascertainment study to investigate household transmission of influenza virus in Managua, Nicaragua. We collected up to 5 respiratory swab samples from each of 536 household contacts of 133 influenza virus-infected persons and assessed for evidence of influenza virus transmission. The overall risk for influenza virus infection of household contacts was $15.7 \%$ (95\% Cl 12.7\%-19.0\%). 
Oseltamivir treatment of index patients did not appear to reduce household transmission. The mean serial interval for within-household transmission was $3.1(95 \% \mathrm{Cl}$ 1.6-8.4) days. We found the transmissibility of influenza $B$ virus to be higher than that of influenza A virus among children. Compared with households with $<4$ household contacts, those with $\geq 4$ household contacts appeared to have a reduced risk for infection. Further research is needed to model household influenza virus transmission and design interventions for these settings.

$\mathrm{I}$ nfluenza virus is a respiratory pathogen of major medical and public health concern, causing an estimated 3-5 million cases of severe illness and 250,000-500,000 deaths annually worldwide (1). Households provide a convenient and valuable setting for studying the transmission of influenza virus (2-5). Several studies in high-income country settings suggest that the rate of influenza virus transmission in the household is several-fold higher than that in the community $(3,4)$. In a study conducted in Vietnam, $26 \%$ of influenza virus infections were acquired in the household (6). The influence of household transmission on influenza epidemics has led to an increased interest in household-based interventions (7-11). However, in low-income and low-middle-income countries, where nearly half the world's population lives, household influenza transmission has not been well studied. Moreover, estimates of the serial interval (i.e., time between index case and symptom onset in secondary infection) are limited to pandemic influenza in nonhousehold settings $(6,12-15)$. Therefore, a more thorough investigation of household transmission is essential for the development of effective household-based interventions for the control of pandemic and interpandemic influenza in these settings.

Demographic factors that have been found to influence influenza transmission include the size of the household, age of the index patient, and age of contacts (4,6,16-19). Both household size and population demographics differ dramatically between industrialized and developing country settings. In Nicaragua, persons from several generations often live in the same household, leading to large household sizes by high-income country standards. In addition, in $2014, \approx 32 \%$ of the population of Nicaragua was $<15$ years of age, whereas in other countries where influenza household transmission studies have been conducted, $12 \% 23 \%$ of the population was estimated to be in this age range $(5,6,20-22)$.

To investigate influenza transmission in households, we performed a case ascertainment study of influenza in urban households in Managua, Nicaragua. We used an individual-based hazard model to characterize transmission dynamics within households and estimate factors affecting influenza transmission.

\section{Materials and Methods}

\section{Study Subjects}

Index influenza cases were identified at the Health Center Sócrates Flores Vivas, a primary care facility in Managua, Nicaragua, run by the Ministry of Health of Nicaragua. Index patients were eligible for enrollment if a) they had influenza-like illness, defined as fever or feverishness with cough, sore throat, or runny nose; 2) their symptom onset, defined as the earliest day with influenza-like illness, was within the previous 48 hours; 3 ) they were positive for influenza by rapid antigen test or reverse transcription PCR (RT-PCR); 4) no household members had had symptoms of influenza-like illness in the previous 2 weeks; and 5) they lived with $\geq 1$ additional person. After index case enrollment, we conducted a household visit to enroll patient household contacts, collect initial respiratory and blood samples, and administer questionnaires to the household and individual household members. We defined a household as a group of persons living together who shared a kitchen and $\geq 1$ meal a day. We visited households 4 additional times (every 2-3 days) to collect respiratory samples and daily symptom information, and we collected the final blood sample 30-45 days after index case enrollment.

This study was approved by the institutional review boards at the Ministry of Health of Nicaragua, the University of Michigan (Ann Arbor, Michigan, USA), and the University of California, Berkeley (Berkeley, California, USA). Consent to participate was obtained from all adult participants, and parental permission was obtained for all children. Assent was obtained for children $\geq 6$ years of age.

\section{Laboratory Methods}

We stored nasal and throat swab samples at $4{ }^{\circ} \mathrm{C}-8^{\circ} \mathrm{C}$ and transported them to the National Virology Laboratory (Managua, Nicaragua) within 12 hours. We tested all samples for influenza on an ABI 7500 Fast PCR platform (Applied Biosystems, Foster City, CA, USA) following validated protocols from the US Centers for Disease Control and Prevention (Atlanta, GA, USA).

\section{Statistical Analysis}

We characterized influenza transmission dynamics within households and the effects of factors affecting transmission using an individual-based hazard model $(5,17)$. In the model, the risk for RT-PCR-confirmed infection among household contacts depended on the time from symptom onset of other infected persons in the household. The hazard $(\lambda)$ of infection of person $j$ at time $t$ from an infected household member $i$, with symptom onset $t_{i}$ is $\lambda_{i \circledast j}(t)=\lambda_{n} \times S_{j}$, where $\lambda_{n}$ is the baseline hazard of household transmission and $S_{j}$ is the factors affecting transmissibility. 
The distribution of the serial interval was a discretized Weibull distribution (23), with probability mass function

$$
f_{i}(t)=\exp \left(-\left(\frac{t}{\gamma}\right)^{\alpha}\right)-\exp \left(-\left(\frac{t+1}{\gamma}\right)^{\alpha}\right), t>t_{i},
$$

where $t$ is the number of days after symptom onset of the index patient, $\boldsymbol{\alpha}$ is the shape, and $\gamma$ is the scale parameter for the distribution. The model used to estimate the distribution included infection of household contacts by persons inside the household (index cases [i.e., secondary infections] and other infected household members [i.e., tertiary infections]) and outside the household (i.e., community infections). The hazard of infection from the community was assumed to be constant over the duration of the follow-up: $\lambda_{j, c}(t)=\psi$, where $\psi$ is the baseline community risk (5). Therefore, the hazard of infection for a person $j$ at day $t$ is $\lambda_{j}(t)=\lambda_{j, c}(t)+\stackrel{\circ}{a}_{i} \lambda_{i \circledast j}(t)$, and the summation involves the infected household contacts of person $j$ only.

In the transmission model, age group $(\leq 18$ years vs. $>18$ years) and vaccination status of the household contacts were factors that might affect the susceptibility of household contacts to infection $(5,17)$. In addition, we accounted for the possible differences in transmission related to the different influenza virus types [influenza $\mathrm{A}(\mathrm{H} 1 \mathrm{~N} 1)$, influenza $\mathrm{A}(\mathrm{H} 3 \mathrm{~N} 2)$, and influenza $\mathrm{B}$ ]; treatment (with vs. without oseltamivir) of index case; index patient age group (children $\leq 5$ years of age vs. older children and adults); and household sizes, hereafter denoted as the preliminary analysis. In addition to these factors, we further explored the differences in the relative susceptibilities of children and adults to influenza types $\mathrm{A}$ and $\mathrm{B}$, which was represented by an interaction of age and influenza types in the model. We considered this analysis the main analysis (online Technical Appendix, https://wwwnc.cdc.gov/EID/article/ 24/10/16-1258-Techapp1.pdf).

We fitted this model into a Bayesian framework, constructed a Markov chain Monte Carlo algorithm, and estimated parameters (24). We used conditional likelihood in the statistical model to account for the study design feature that no household contacts had symptom onset at or before the day of index case enrollment (online Technical Appendix). To evaluate model adequacy, we conducted a simulation study with the model to compare the estimated and observed risks of groups with different characteristics (online Technical Appendix). We performed statistical analyses with $\mathrm{R}$ version 3.1.1 (https://cran.r-project.org/) and MATLAB version 7.8.0 (https://www.mathworks.com/products/matlab.html).

\section{Results}

During August 2012-November 2014, a total of 168 potential index patients consented to participate in the study. We excluded 6 households with multiple index cases, 5 households with influenza virus infections of mixed subtypes, and 24 households with index cases that were initially positive for influenza by rapid antigen test but not confirmed positive by RT-PCR. In total, 133 households with index cases of influenza virus infection confirmed by RT-PCR were included in our analysis (Figure 1). At the initial visit, 541 household contacts were present, and 536 (99\%) were enrolled. A total of 2,285 respiratory samples were collected from household contacts (mean 4.3 respiratory samples/contact). Of the 356 household contacts, 84 (15.7\%, 95\% CI 12.7\%-19.0\%) had RT-PCR-confirmed influenza virus infections (Table 1). Of these, 21 (25\%) did not exhibit symptoms. Influenza transmission was observed in $52(39 \%)$ households. Of the households with influenza transmission, 34 had 1 contact with an RT-PCR-confirmed influenza virus infection, 10 had 2 contacts, and 8 had $\geq 3$ contacts. Most index cases (76\%) were managed with oseltamivir. The average age of index patients was 6.6 (range $0-45)$ years, and the average age of household contacts was 24.2 (range 0-87) years. Mean household size was 5.0 (range 2-17) members. Among household contacts, the overall observed risk for influenza $\mathrm{A}(\mathrm{H} 1 \mathrm{~N} 1)$ virus infection was $13.4 \%(9 / 67,95 \%$ CI $6.3 \%-24.0 \%)$, influenza A(H3N2) virus $14.3 \%(46 / 322,95 \%$ CI $10.7 \%-18.6 \%)$, and influenza B virus $19.7 \%$ (29/147, 95\% CI 13.6\%-27.1\%).

In the preliminary analysis, we adjusted for age group of household contacts, vaccination history, index patient age group, index case treatment status, and household contact number but did not include the interaction of age group of household contacts and influenza type and subtype. In this analysis, we found that household contacts of index patients with RT-PCR-confirmed influenza B virus infections were more likely to get infected than those of index patients with influenza $\mathrm{A}(\mathrm{H} 3 \mathrm{~N} 2)$ virus infections (relative infectivity $1.71,95 \%$ CI $1.08-2.80)$ or influenza $\mathrm{A}(\mathrm{H} 1 \mathrm{~N} 1)$ virus infections (relative infectivity $1.56,95 \%$ CI $0.75-3.43$ ).

In the main model, we included the interaction of age group of household contacts and influenza type, which

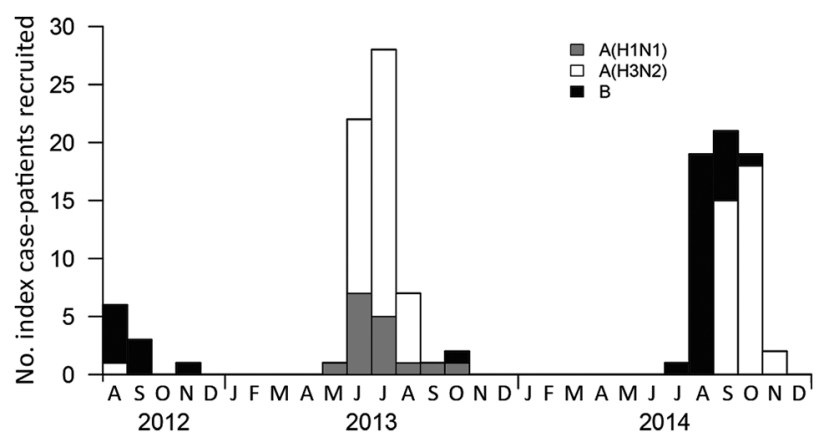

Figure 1. Timeline of enrollment of index cases of PCR-confirmed monoinfections of seasonal influenza $\mathrm{A}(\mathrm{H} 1 \mathrm{~N} 1)$ virus, influenza $\mathrm{A}(\mathrm{H} 3 \mathrm{~N} 2)$ virus, or influenza B virus, Managua, Nicaragua, August 2012-November 2014. Only the index cases included in the final analysis are shown. 
Table 1. Characteristics of influenza virus-infected index cases-patients and household contacts, Managua, Nicaragua, August 2012November 2014*

\begin{tabular}{|c|c|c|c|c|}
\hline \multirow[b]{2}{*}{ Characteristic } & \multicolumn{3}{|c|}{ Influenza type, no./total (\%) } & \multirow[b]{2}{*}{ Total, no. (\%) } \\
\hline & $\mathrm{A}(\mathrm{H} 1 \mathrm{~N} 1)$ & $\mathrm{A}(\mathrm{H} 3 \mathrm{~N} 2)$ & $\mathrm{B}$ & \\
\hline Index patients & 16 & 80 & 37 & 133 \\
\hline \multicolumn{5}{|l|}{ Age, y } \\
\hline$\leq 5$ & $10(63)$ & $52(65)$ & $15(41)$ & $77(58)$ \\
\hline$\overline{6}-18$ & $5(31)$ & $23(29)$ & $21(57)$ & 49 (37) \\
\hline$>18$ & $1(6)$ & $5(6)$ & $1(3)$ & $7(5)$ \\
\hline \multicolumn{5}{|l|}{ Sex } \\
\hline $\mathrm{F}$ & $6(38)$ & $36(45)$ & $17(46)$ & $59(44)$ \\
\hline $\mathrm{M}$ & $10(63)$ & $44(55)$ & $20(54)$ & $74(56)$ \\
\hline \multicolumn{5}{|l|}{ Prior vaccination } \\
\hline Yes & $1(6)$ & $2(3)$ & $3(8)$ & $6(5)$ \\
\hline No & $15(94)$ & $78(98)$ & $34(92)$ & $127(95)$ \\
\hline \multicolumn{5}{|c|}{ Oseltamivir treatment } \\
\hline Yes & $16(100)$ & $53(66)$ & $32(86)$ & $101(76)$ \\
\hline No & 0 & $27(34)$ & $5(14)$ & $32(24)$ \\
\hline \multicolumn{5}{|c|}{ No. household contacts } \\
\hline $1-3$ & $6(38)$ & $44(55)$ & $23(62)$ & $73(55)$ \\
\hline $4-5$ & $5(31)$ & $19(24)$ & $6(16)$ & $30(23)$ \\
\hline$>5$ & $5(31)$ & $17(21)$ & $8(22)$ & $30(23)$ \\
\hline \multicolumn{5}{|c|}{ No. secondary cases in household } \\
\hline 0 & $10(63)$ & $54(68)$ & $17(46)$ & $81(61)$ \\
\hline 1 & $4(25)$ & $16(20)$ & $14(38)$ & $34(26)$ \\
\hline 2 & $1(6)$ & $4(5)$ & $5(14)$ & $10(8)$ \\
\hline$>2$ & $1(6)$ & $6(8)$ & $1(3)$ & $8(6)$ \\
\hline Household contacts & 67 & 322 & 147 & 536 \\
\hline \multicolumn{5}{|l|}{ Age, y } \\
\hline$\leq 18$ & $30(45)$ & $147(46)$ & $64(44)$ & $241(45)$ \\
\hline$>18$ & $37(55)$ & $175(54)$ & $83(56)$ & $295(55)$ \\
\hline \multicolumn{5}{|l|}{ Sex } \\
\hline $\mathrm{F}$ & $46(69)$ & $202(63)$ & $94(64)$ & $342(64)$ \\
\hline $\mathrm{M}$ & $21(31)$ & $120(37)$ & $53(36)$ & $194(36)$ \\
\hline \multicolumn{5}{|l|}{ Prior vaccination } \\
\hline Yes & $3(4)$ & $9(3)$ & $20(14)$ & $32(6)$ \\
\hline No & $64(96)$ & $313(97)$ & $127(86)$ & $504(94)$ \\
\hline \multicolumn{5}{|c|}{ With confirmed infection } \\
\hline Overall & $9 / 67(13)$ & $46 / 322(14)$ & $29 / 147(20)$ & $84 / 536$ (16) \\
\hline$\leq 18 \mathrm{y} \dagger$ & $3 / 30$ (10) & $33 / 147(22)$ & $21 / 64$ (33) & $57 / 241(24)$ \\
\hline$>18 \mathrm{y} \dagger$ & $6 / 37$ (16) & $13 / 175$ (7) & $8 / 83(10)$ & $27 / 295(9)$ \\
\hline \multicolumn{5}{|c|}{ No. confirmed infections without reported symptoms } \\
\hline Overall & $2 / 9(22)$ & 15/46 (33) & $4 / 29(14)$ & $21 / 84(25)$ \\
\hline$\leq 18 \mathrm{y} \dagger$ & $2 / 3(67)$ & $11 / 33(33)$ & $3 / 21(14)$ & $16 / 57(28)$ \\
\hline$>18$ y & $0 / 6$ & $4 / 13(31)$ & $1 / 8(13)$ & $5 / 27(19)$ \\
\hline
\end{tabular}

${ }^{*}$ Not all percentages add up to $100 \%$ because of rounding.

†The denominator is the number of infected household contacts in the corresponding age group.

accounted for the difference in relative susceptibility between children and adults for influenza A and influenza B. Using this model, we found no differences in risk for infection between influenza $\mathrm{A}(\mathrm{H} 3 \mathrm{~N} 2)$ virus and influenza $\mathrm{A}(\mathrm{H} 1 \mathrm{~N} 1)$ virus or influenza B virus (Table 2). This finding suggested that the observed increased susceptibility to infection with influenza B virus could be explained by an interaction between age of household contacts and influenza type; in other words, child contacts were more susceptible to infection with influenza B virus than influenza A virus, and among adult contacts, the risk for infection with influenza $A$ virus was similar to the risk for infection with influenza $B$ virus.

We estimated that child household contacts $(\leq 18$ years of age) were more susceptible to RT-PCR-confirmed influenza A virus infection than adult contacts $(>18$ years of age) (relative susceptibility $2.26,95 \%$ CI $1.38-3.88$ ), and child contacts were more susceptible to RT-PCR-confirmed influenza $\mathrm{B}$ virus infection than adult contacts (relative susceptibility $4.47,95 \%$ CI $2.05-11.02)$. Because there were only 7 adult index patients (Table 1), we could not explore potential differences in infectivity of child versus adult cases. However, we did explore relative infectivity of younger children ( $\leq 5$ years of age) versus older children and adults; the estimated relative infectivity of younger children was 1.55 (95\% CI 0.98-2.45) (Table 2).

We found no statistically significant association between oseltamivir treatment of index patients and risk for infection among household contacts (risk ratio $0.69,95 \% \mathrm{CI}$ $0.42-1.12)$. We estimated vaccine effectiveness among vaccinated household contacts as $54 \%$ (95\% CI $-32 \%$ to $89 \%)$. Household contacts of index patients having $\geq 4$ household contacts had $\approx 30 \% \quad 40 \%$ lower risk for infection than those 
Table 2. Factors affecting influenza transmission in urban households, Managua, Nicaragua, August 2012-November 2014

\begin{tabular}{lc}
\hline Characteristics & Risk ratio $(95 \% \mathrm{Cl})$ \\
\hline Influenza type & Referent \\
$\mathrm{A}(\mathrm{H} 3 \mathrm{~N} 2)$ & $1.18(0.5-2.42)$ \\
$\mathrm{A}(\mathrm{H} 1 \mathrm{~N} 1)$ & $0.96(0.4-2.15)$ \\
$\mathrm{B}$ & Referent \\
\hline Age of household contact, $\mathrm{y}$ & $2.26(1.38-3.88)$ \\
$>18$ & $4.47(2.05-11.02)$ \\
$\leq 18$ for influenza A & \\
$\leq 18$ for influenza B & Referent \\
\hline Prior vaccination of household contact & $0.46(0.11-1.32)$ \\
No & Referent \\
Yes & $1.55(0.98-2.45)$ \\
\hline Age of index patient, y & \\
$\leq 5$ & Referent \\
$>5$ & $0.69(0.42-1.12)$ \\
\hline Oseltamivir treatment of index case & \\
No & Referent \\
Yes & $0.60(0.30-1.10)$ \\
\hline No. household contacts & $0.69(0.37-1.18)$ \\
$1-3$ &
\end{tabular}

of index patients having $<4$ household members, but this difference was not statistically significant (Table 2; online Technical Appendix Table). We estimated that the mean serial interval for within-household transmission was 3.1 (95\% CI 1.6-8.4) days (SD 2.0 [95\% CI 0.4-10.8] days).

We performed simulation studies to assess the adequacy of our model (Figure 2). The median estimated risks for infection among groups from the 10,000 simulated household epidemics were close to the risks observed, suggesting our model provided a reasonable fit of the data.

\section{Discussion}

We describe the results from a case ascertainment study of influenza transmission in urban households of Nicaragua. In this setting, we found the mean serial interval for withinhousehold influenza transmission to be 3.1 days. We further observed an overall risk for RT-PCR-confirmed influenza virus infection of $\approx 16 \%$ among household contacts of index patients with RT-PCR-confirmed influenza virus infections, despite high oseltamivir treatment of index patients $(76 \%)$.

We found evidence that influenza B virus was more transmissible than influenza A virus, which was explainable by higher transmissibility of this virus among children (Table 2). As expected, children were more susceptible to influenza A and influenza B than adults in our study, presumably because of lower levels of preexisting immunity
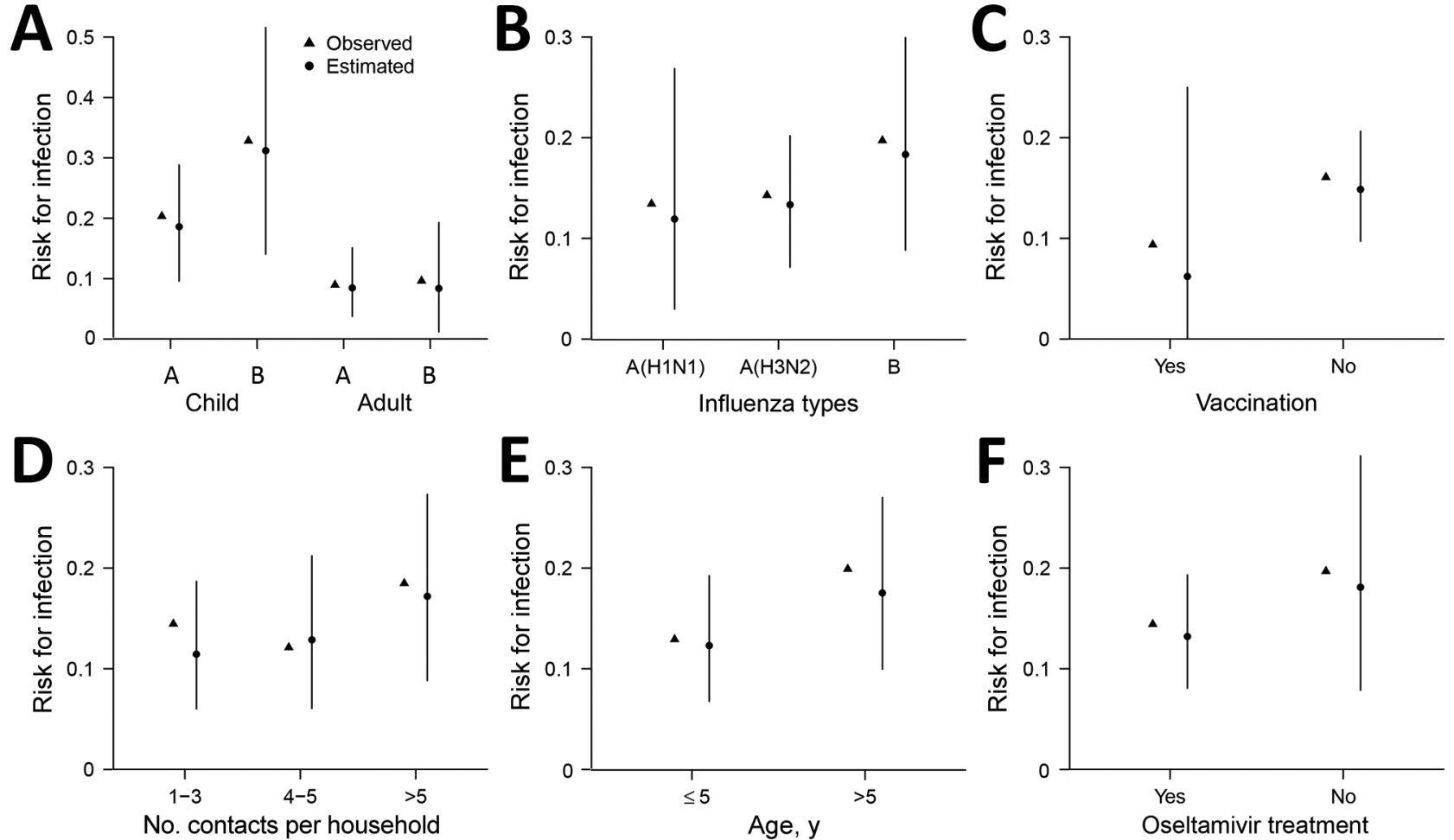

Figure 2. Observed and estimated risks for influenza virus infection of household contacts of index patients with reverse transcription PCR-confirmed influenza virus infections, by characteristic, Managua, Nicaragua, August 2012-November 2014. We estimated risk for infection by performing simulations using a multivariate model fitted to the collected data. Estimates represent 10,000 simulated epidemics in households with a structure that matched exactly that of the observed household. Points indicate medians, and bars represent the $2.5 \%-$ $97.5 \%$ ranges of those 10,000 simulations. Risks for infection are shown for $A$ ) child and adult household contacts with influenza $A$ virus infection or influenza B virus infection; B) virus type and subtype; C) vaccinated and nonvaccinated household contacts; D) household contact number; E) age group; and F) household contacts of index patients who were and were not treated with oseltamivir. 
and different contact patterns (25). This finding is consistent with those of other studies $(4,6,16,17)$. However, a large randomized controlled trial in households in Thailand did not observe significant differences between children and adults in risk for influenza virus infection (10).

We did not detect a significant effect for oseltamivir treatment of index patients on influenza transmissibility. This observation is consistent with several other household transmission studies that have found that oseltamivir treatment decreases the infectious period but does not have a statistically significant effect on the secondary attack rate of laboratory-confirmed influenza $(19,26,27)$. However, other studies have shown a reduction in household transmission from index patients treated with oseltamivir $(28,29)$. In a review, about half of household transmission studies reported a significant association between index case oseltamivir treatment and reduction in transmission in households, suggesting this issue is still unresolved (30). On the other hand, our study might be underpowered to detect this association, considering that $76 \%$ of the index patients were treated with oseltamivir.

We did not observe that vaccination had a significant effect on influenza transmission in the household. However, the proportion of contacts vaccinated in this study was low $(5 \%)$, and thus, the study was underpowered to detect vaccine effectiveness in this population.

We did not find a statistically significant association between risk of acquiring an infection and number of household contacts, although the point estimate suggests that the risk for infection among household contacts of index patients with $\geq 4$ household contacts was $30 \%-40 \%$ lower than those of index patients with $<4$ household contacts. This association has also been reported in other studies. The absence of this association in a study might indicate insufficient sample size (4-6).

We estimated the mean serial interval for influenza in households in Nicaragua to be 3.1 days. This estimate is similar to those found in other settings, such as Hong Kong, where the mean serial interval estimate for influenza A was 3.2-3.6 days $(16,21,22)$; Thailand, where the estimate was 3.3-3.7 days, depending on the type and subtype of influenza (31); and Michigan, where the mean serial interval reported was 3.2 days (32). In a review of influenza $\mathrm{A}(\mathrm{H} 1 \mathrm{~N} 1)$ pdm09 virus transmission, the mean serial interval was estimated to be 2.6 days (33).

A major strength of our study was the collection of up to 5 respiratory samples from each household contact, regardless of whether they had symptoms, for 9-12 days after index case identification. However, our study has several limitations, the most notable being that we enrolled index influenza cases only among persons seeking medical care. This aspect of the study design could have biased the study toward sicker than average index patients, which could have inflated our influenza transmission estimate. Also, because adults tend to seek treatment later in their illnesses than children and enrollment was limited to index patients who sought treatment $\leq 2$ days after symptom onset, our study was overrepresented by index cases in children. This enrollment criterion could have also led to an increase in the intensity of transmission and shortened the observed serial interval of transmission (4). Last, not enough adult index cases were enrolled to examine whether child index cases might be more infectious than adult index cases.

In summary, in this household transmission study of influenza in Managua, Nicaragua, we observed a high secondary attack rate of influenza and a serial interval within the range of those observed in high-income country settings. Our findings extend the relatively limited knowledge available regarding influenza transmission in low-middleincome countries. Further research is needed to investigate how household conditions affect influenza transmission and to design household-based interventions in these settings.

\section{Acknowledgments}

We thank the families that participated in the study and our excellent study staff at the Health Center Sócrates Flores Vives and Centro Nacional de Diagnóstico y Referencia.

This work was supported by the National Institute of Allergy and Infectious Diseases, National Institutes of Health (grant no. U01AI088654 to A.G. and E.H. and contract no. HHSN272201 400006C subcontracted to A.G.); the Research Grants Council of the Hong Kong Special Administrative Region, China (project no. T11-705/14N to B.J.C.), Harvard Center for Communicable Disease Dynamics from the National Institute of General Medical Sciences (grant no. U54 GM088558 to B.J.C.), and a career development award from the John E. Fogarty International Center, National Institutes of Health (K02 TW009483 to A.G.).

Conflicts of interest: A.G. has received consultancy fees from Abt Associates for a Centers for Disease Control and Preventionfunded influenza study. B.J.C. received research funding from MedImmune Inc. and Sanofi Pasteur and consults for Crucell NV. All other authors report no potential conflicts of interest.

\section{About the Author}

Dr. Gordon is an assistant professor at the University of Michigan, Ann Arbor, Michigan, USA. Her research interests are the areas of infectious disease epidemiology and global health, with a focus on influenza burden and transmission.

\section{References}

1. World Health Organization. Influenza (seasonal). 2018 Jan 31 [cited 2016 Jul 28]. http://www.who.int/mediacentre/factsheets/fs211/en/

2. Longini IM Jr, Koopman JS, Haber M, Cotsonis GA. Statistical inference for infectious diseases. Risk-specific household and community transmission parameters. Am J Epidemiol. 
1988;128:845-59. http://dx.doi.org/10.1093/oxfordjournals. aje.a115038

3. Longini IM Jr, Koopman JS, Monto AS, Fox JP. Estimating household and community transmission parameters for influenza. Am J Epidemiol. 1982;115:736-51. http://dx.doi.org/10.1093/ oxfordjournals.aje.a113356

4. Cauchemez S, Carrat F, Viboud C, Valleron AJ, Boëlle PY. A Bayesian MCMC approach to study transmission of influenza: application to household longitudinal data. Stat Med. 2004;23:3469-87. http://dx.doi.org/10.1002/sim.1912

5. Cauchemez S, Donnelly CA, Reed C, Ghani AC, Fraser C, Kent CK, et al. Household transmission of 2009 pandemic influenza A (H1N1) virus in the United States. N Engl J Med. 2009;361:2619-27. http://dx.doi.org/10.1056/NEJMoa0905498

6. Cauchemez S, Ferguson NM, Fox A, Mai Q, Thanh T, Thai PQ, et al. Determinants of influenza transmission in South East Asia: insights from a household cohort study in Vietnam. PLoS Pathog. 2014;10:e1004310. http://dx.doi.org/10.1371/journal.ppat.1004310

7. Wu JT, Riley S, Fraser C, Leung GM. Reducing the impact of the next influenza pandemic using household-based public health interventions. PLoS Med. 2006;3:e361. http://dx.doi.org/10.1371/ journal.pmed.0030361

8. Cowling BJ, Chan KH, Fang VJ, Cheng CK, Fung RO, Wai W, et al. Facemasks and hand hygiene to prevent influenza transmission in households: a cluster randomized trial. Ann Intern Med. 2009;151:437-46. http://dx.doi.org/10.7326/0003-4819-1517-200910060-00142

9. Ng S, Cowling BJ, Fang VJ, Chan KH, Ip DK, Cheng CK, et al. Effects of oseltamivir treatment on duration of clinical illness and viral shedding and household transmission of influenza virus. Clin Infect Dis. 2010;50:707-14. http://dx.doi.org/10.1086/650458

10. Simmerman JM, Suntarattiwong P, Levy J, Jarman RG, Kaewchana S, Gibbons RV, et al. Findings from a household randomized controlled trial of hand washing and face masks to reduce influenza transmission in Bangkok, Thailand. Influenza Other Respi Viruses. 2011;5:256-67. http://dx.doi.org/10.1111/ j.1750-2659.2011.00205.x

11. MacIntyre CR, Cauchemez S, Dwyer DE, Seale H, Cheung P, Browne $\mathrm{G}$, et al. Face mask use and control of respiratory virus transmission in households. Emerg Infect Dis. 2009;15:233-41. http://dx.doi.org/10.3201/eid1502.081166

12. Thai PQ, Mai Q, Welkers MR, Hang NK, Thanh T, Dung VT, et al. Pandemic H1N1 virus transmission and shedding dynamics in index case households of a prospective Vietnamese cohort. J Infect. 2014;68:581-90. http://dx.doi.org/10.1016/j.jinf.2014.01.008

13. Andayi F, Crepey P, Kieffer A, Salez N, Abdo AA, Carrat F, et al. Determinants of individuals' risks to 2009 pandemic influenza virus infection at household level amongst Djibouti city residentsa CoPanFlu cross-sectional study. Virol J. 2014;11:13. http://dx.doi.org/10.1186/1743-422X-11-13

14. Kieffer A, Paboriboune P, Crépey P, Flaissier B, Souvong V, Steenkeste N, et al. $2009 \mathrm{~A}(\mathrm{H} 1 \mathrm{~N} 1)$ seroconversion rates and risk factors among the general population in Vientiane Capital, Laos. PLoS One. 2013;8:e61909. http://dx.doi.org/10.1371/journal.pone.0061909

15. Asiedu-Bekoe F, Adu DA, Offei A. Mass oseltamivir prophylaxis halts pandemic influenza A H1N1 2009 outbreak in a secondary school in Ashanti Region, Ghana. Ghana Med J. 2012;46:219-24.

16. Lau MS, Cowling BJ, Cook AR, Riley S. Inferring influenza dynamics and control in households. Proc Natl Acad Sci U S A. 2015;112:9094-9. http://dx.doi.org/10.1073/pnas.1423339112

17. Tsang TK, Cauchemez S, Perera RA, Freeman G, Fang VJ, Ip DK, et al. Association between antibody titers and protection against influenza virus infection within households. J Infect Dis. 2014;210:684-92. http://dx.doi.org/10.1093/infdis/jiu186

18. Hirotsu N, Wada K, Oshitani H. Risk factors of household transmission of pandemic (H1N1) 2009 among patients treated with antivirals: a prospective study at a primary clinic in Japan. PLoS One. 2012;7:e31519. http://dx.doi.org/10.1371/ journal.pone. 0031519

19. Nishiura $H$, Oshitani $H$. Household transmission of influenza (H1N1-2009) in Japan: age-specificity and reduction of household transmission risk by zanamivir treatment. J Int Med Res. 2011;39:619-28. http://dx.doi.org/10.1177/147323001103900231

20. The World Bank. Population ages 0-14 (\% of total). 2017 [cited 2015 Jul 23]. http://data.worldbank.org/indicator/SP.POP.0014.TO.ZS

21. Cowling BJ, Chan KH, Fang VJ, Lau LLH, So HC, Fung ROP, et al. Comparative epidemiology of pandemic and seasonal influenza A in households. N Engl J Med. 2010;362:2175-84. http://dx.doi.org/10.1056/NEJMoa0911530

22. Cowling BJ, Fang VJ, Riley S, Malik Peiris JS, Leung GM. Estimation of the serial interval of influenza. Epidemiology. 2009;20:344-7. http://dx.doi.org/10.1097/EDE.0b013e31819d1092

23. Cauchemez S, Donnelly CA, Reed C, Ghani AC, Fraser C, Kent CK, et al. Household transmission of 2009 pandemic influenza A (H1N1) virus in the United States. N Engl J Med. 2009;361:2619-27. http://dx.doi.org/10.1056/NEJMoa0905498

24. Gilks WR, Richardson S, Spiegelhalter DJ. Markov chain Monte Carlo in practice. Interdisciplinary statistics. London: Chapman \& Hall; 1995.

25. Mossong J, Hens N, Jit M, Beutels P, Auranen K, Mikolajczyk R, et al. Social contacts and mixing patterns relevant to the spread of infectious diseases. PLoS Med. 2008;5:e74. http://dx.doi.org/ 10.1371/journal.pmed.0050074

26. Fry AM, Goswami D, Nahar K, Sharmin AT, Rahman M, Gubareva L, et al. Effects of oseltamivir treatment of index patients with influenza on secondary household illness in an urban setting in Bangladesh: secondary analysis of a randomised, placebo-controlled trial. Lancet Infect Dis. 2015;15:654-62. http://dx.doi.org/10.1016/S1473-3099(15)70041-1

27. Ng S, Cowling BJ, Fang VJ, Chan KH, Ip DKM, Cheng CKY, et al. Effects of oseltamivir treatment on duration of clinical illness and viral shedding and household transmission of influenza virus. Clin Infect Dis. 2010;50:707-14. http://dx.doi.org/10.1086/650458

28. Halloran ME, Hayden FG, Yang Y, Longini IM Jr, Monto AS. Antiviral effects on influenza viral transmission and pathogenicity: observations from household-based trials. Am J Epidemiol. 2007;165:212-21. http://dx.doi.org/10.1093/aje/kwj362

29. Teh B, Olsen K, Black J, Cheng AC, Aboltins C, Bull K, et al. Impact of swine influenza and quarantine measures on patients and households during the H1N1/09 pandemic. Scand J Infect Dis. 2012;44:289-96. http://dx.doi.org/10.3109/00365548.2011.631572

30. Tsang TK, Lau LLH, Cauchemez S, Cowling BJ. Household transmission of influenza virus. Trends Microbiol. 2016;24:123-33. http://dx.doi.org/10.1016/j.tim.2015.10.012

31. Levy JW, Cowling BJ, Simmerman JM, Olsen SJ, Fang VJ, Suntarattiwong P, et al. The serial intervals of seasonal and pandemic influenza viruses in households in Bangkok, Thailand. Am J Epidemiol. 2013;177:1443-51. http://dx.doi.org/10.1093/aje/ kws402

32. Petrie JG, Ohmit SE, Cowling BJ, Johnson E, Cross RT, Malosh RE, et al. Influenza transmission in a cohort of households with children: 2010-2011. PLoS One. 2013;8:e75339. http://dx.doi.org/10.1371/journal.pone.0075339

33. Boëlle PY, Ansart S, Cori A, Valleron AJ. Transmission parameters of the A/H1N1 (2009) influenza virus pandemic: a review. Influenza Other Respi Viruses. 2011;5:306-16. http://dx.doi.org/10.1111/j.1750-2659.2011.00234.x

Address for correspondence: Aubree Gordon, University of Michigan, Epidemiology, 1415 Washington Heights, Ann Arbor, MI 48109, USA; email: gordonal@umich.edu 